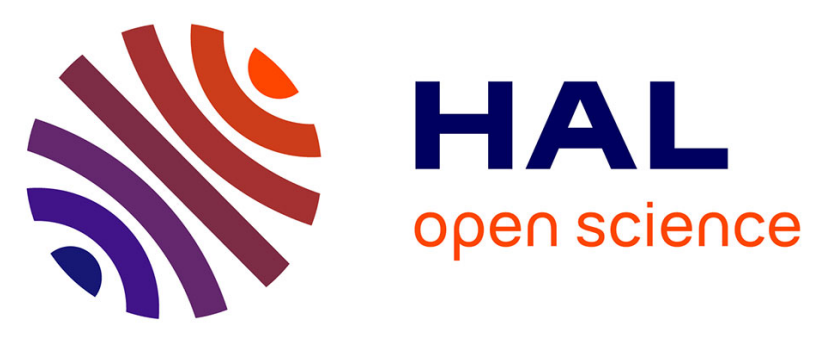

\title{
Biologics in myelodysplastic syndrome-related systemic inflammatory and autoimmune diseases: French multicenter retrospective study of 29 patients
}

Arsene Mekinian, Guillaume Dervin, Nathanael Lapidus, Jean-Emmanuel Kahn, Louis Terriou, Eric Liozon, Eric Grignano, Jean-Charles Piette, Odile Beyne Rauzy, Vincent Grobost, et al.

\section{To cite this version:}

Arsene Mekinian, Guillaume Dervin, Nathanael Lapidus, Jean-Emmanuel Kahn, Louis Terriou, et al.. Biologics in myelodysplastic syndrome-related systemic inflammatory and autoimmune diseases: French multicenter retrospective study of 29 patients. Autoimmunity Reviews, 2017, 10.1016/j.autrev.2017.07.003 . hal-01563947

\section{HAL Id: hal-01563947 \\ https://hal.sorbonne-universite.fr/hal-01563947}

Submitted on 18 Jul 2017

HAL is a multi-disciplinary open access archive for the deposit and dissemination of scientific research documents, whether they are published or not. The documents may come from teaching and research institutions in France or abroad, or from public or private research centers.
L'archive ouverte pluridisciplinaire HAL, est destinée au dépôt et à la diffusion de documents scientifiques de niveau recherche, publiés ou non, émanant des établissements d'enseignement et de recherche français ou étrangers, des laboratoires publics ou privés. 


\section{Biologics in Myelodysplastic Syndrome-related Systemic Inflammatory and Autoimmune Diseases: French Multicenter Retrospective Study of 29 Patients}

Arsene Mekinian ${ }^{1 *}$, Guillaume Dervin ${ }^{1 *}$, Nathanael Lapidus ${ }^{2}$, Jean-Emmanuel $\mathrm{Kahn}^{3}$, Louis Terriou $^{4}$, Eric Liozon ${ }^{5}$, Eric Grignano ${ }^{1}$, Jean-Charles Piette ${ }^{6}$, Odile Beyne Rauzy ${ }^{7}$, Vincent Grobost $^{8}$, Pascal Godmer ${ }^{9}$, Jerome Gillard ${ }^{10}$, Julien Rossignol ${ }^{11}$, David Launay ${ }^{4}$, Achille Aouba $^{12}$, Thierry Cardon ${ }^{13}$, Laurence Bouillet ${ }^{14}$, Jonathan Broner ${ }^{15}$, Julien Vinit ${ }^{16}$, Lionel Ades ${ }^{17}$, Fabrice Carrat ${ }^{2}$, Clementine Salvado ${ }^{18}$, Eric Toussirot ${ }^{19}$, Mathilde Versini ${ }^{20}$, Nathalie CostedoatChalumeau $^{21}$, Jean Baptiste Fraison ${ }^{21}$, Philippe Guilpain ${ }^{15}$, Pierre Fenaux ${ }^{17}$, Olivier Fain ${ }^{1 * *}$, on behalf of GFM, SNFMI, CRI and MINHEMON

${ }^{1}$ Service de Médecine Interne, Hôpital Saint Antoine, APHP, Université Paris 6, 75012 Paris, France.

${ }^{2}$ Service de Biostatistiques, Hôpital Saint Antoine, APHP, Université Paris 6, 75012 Paris, France.

${ }^{3}$ Service de médecine interne, Université Versailles-Saint Quentin en Yvelines, Hôpital Foch, Suresnes, France

${ }^{4}$ Univ. Lille, U995, Lille Inflammation Research International Center (LIRIC), F-59000

Lille, France ; Inserm, U995, F-59000 Lille, France ; CHU Lille, Département de médecine interne et immunologie clinique, F-59000 Lille, France; Centre national de référence maladies systémiques et auto-immunes rares (sclérodermie systémique), F-59000 Lille, France

${ }^{5}$ Service de médecine interne, CHU Dupuytren, Limoges, France

${ }^{6}$ Service de médecine interne, Hôpital Pitié Salpetrière, Université Paris 6, APHP, Paris, France.

${ }^{7}$ Service de médecine interne CHU de Purpan Toulouse, France

${ }^{8}$ Service de médecine interne, CHU Clermont Ferrand, Clermont Ferrand, France.

${ }^{9}$ Service de médecine interne CHU Bretagnes atlantique Vannes, France

${ }^{10}$ Service de médecine interne Centre hospitalier Lons le Saunier 39016 France

${ }^{11}$ Service hématologie Hôpital Necker Enfant Malades Université Paris 5 Paris France

${ }^{12}$ Service de Médecine interne Hôpital Caen, Caen, France

${ }^{13}$ Service de Rhumatologie CHU Lille, Lille, France

${ }^{14}$ Service de médecine interne, CHU Grenoble, Grenoble, France.

${ }^{15}$ Service de médecine interne, Hôpital Saint Eloi, Université de Montpellier, France

${ }^{16}$ Service de médecine interne, CHU Chalon sur Saône 71321 Chalon, France

${ }^{17}$ Service d'hématologie clinique, CHU Avicenne, Bobigny, France

${ }^{18}$ Service hématologie Hôpital Henri Mondor Créteil, France

19 INSERM CIC 1431 Clinical Investigation Center in biotherapy and department of Rheumatology University hospital Besançon, France

${ }^{20}$ Service de médecine interne, CHU Nice, Nice, France

21 AP-HP, Cochin Hospital, Internal Medicine Department, Centre de référence maladies auto-immunes et systémiques rares, Paris, France ; Université Paris Descartes-Sorbonne Paris Cité, Paris, France ; INSERM U 1153, Center for Epidemiology and Statistics Sorbonne Paris Cité (CRESS), Paris, france 


\section{Correspondence and reprint requests to:}

Arsene Mekinian, MD PhD, AP-HP, Hôpital Saint Antoine, service de médecine interne, DHU i2B, F-75012, Paris, France, Phone: + (33) 149282387 Fax: + (33) 149282652. E-mail: arsene.mekinian@aphp.fr

Running title: Biologics in Myelodysplastic Syndrome-related Systemic Inflammatory and Autoimmune Diseases

Key words (4): myelodysplastic syndrome; arthritis, relapsing polychondritis, vasculitis, corticosteroids, biologics

Word count: abstract (249), manuscript (2240), figures (4), tables ().

Conflicts of interest and funding: Arsene Mekinian and Olivier Fain are investigators of a Cellgene-sponsored trial 


\section{$\underline{\text { Abstract }}$}

\section{Background:}

Systemic inflammatory and autoimmune diseases (SIADs) associated with myelodysplastic syndromes are often difficult to treat. Corticosteroids are efficient but only usually at high doses. The use of biologics needs to be specified.

Methods: In a French multicenter retrospective study, we analyzed the efficacy and safety of biologics (tumor necrosis factor- $\alpha[\mathrm{TNF}-\alpha]$ antagonists, tocilizumab, rituximab and anakinra) for SIADs associated with myelodysplastic syndromes (MDSs). Clinical, biological and overall treatment responses were evaluated. When several lines of treatment were used, data were analyzed before and at the end of each treatment line and were pooled to compare overall response among steroids, disease-modifying anti-rheumatic drugs (DMARDs) and biologics.

Results: We included 29 patients (median age 67 years [interquartile range 62-76], 83\% males) with MDS-related SIADs treated with at least one biologic. The MDSs were predominantly refractory anemia with excess blasts 1 (38\%) and refractory cytopenia with multilineage dysplasia (21\%). The SIADs were mainly arthritis $(n=6 ; 20 \%)$, relapsing polychondritis $(n=8 ; 30 \%)$ and vasculitis $(n=10 ; 34 \%)$. During a 3-year median follow-up (IQR 1.3-4.5), a total of 114 lines of treatments were used for all patients: steroids alone (22\%), DMARDs (23\%), TNF- $\alpha$ antagonists (14\%), anakinra (10\%), rituximab (10\%), tocilizumab (7\%) and azacytidine (9\%). Considering all 114 lines, overall response (complete and partial was showed in $54 \%$ cases. Overall response was more frequent with steroids $(78 \%)$ and rituximab (66\%) than DMARDs $(45 \%)$ and other biologics $(33 \%)(\mathrm{p}<0.05)$. Rituximab had better response in vasculitis and TNF- $\alpha$ antagonists in arthritis. During followup, 20 patients $(71 \%)$ presented at least one severe infection.

Conclusion: This nationwide study demonstrates the efficacy of steroids for SIAD-associated MDSs but a high frequency of steroid dependence. The response to biologics seems low, but rituximab and azacytidine seem promising. 


\section{Introduction}

In $15 \%$ to $20 \%$ of cases, myelodysplastic syndromes (MDSs) and chronic myelomonocytic leukemia (CMML) can be associated with systemic inflammatory and autoimmune diseases (SIADs) (1). Treatment for MDS/CMML-related SIADs is challenging because of the underlying cytopenias and risk of infection. Steroid dependence is frequent and the use of steroid-sparing drugs, particularly cyclophosphamide, methotrexate and azathioprine, is limited because of the risk of secondary MDSs $(1,2)$.

Data describing the value and safety of other immunomodulating drugs besides steroids are scarce, particularly disease-modifying anti-rheumatic drugs (DMARDs) and biologics. Biologics are largely used for SIADs without underlying MDSs/CMML, and tumor necrosis factor $\alpha(\mathrm{TNF}-\alpha)$ antagonists were used for MDSs without increasing the risk of leukemia transformation or cytopenias $(3,4)$. Only a few cases reported the interest of biologics in MDS-related SIADs, and large case-series in this topic are lacking (5-7). We recently showed high SIAD response on treating MDSs with azacytidine in steroid-dependent/refractory disease, but these data remain to be confirmed (8).

In this French nationwide study, we report the long-term outcome of 29 patients with MDS/CMML-associated SIADs treated with biologics (TNF- $\alpha$ antagonists, tocilizumab, rituximab and anakinra) and compare the safety and efficacy of the drugs.

\section{PATIENTS AND METHODS}

\section{Patients}

We retrospectively collected data for patients with MDSs/CMML and SIADs followed between 2006 and 2016 in 16 French centers. Cases were recruited through the Société Nationale Francaise de Médecine Interne (SNFMI) and the Club Rhumatismes Inflammation (CRI). Inclusion criteria were SIADs with MDSs/CMML (WHO 2008 classification) treated with at least one biologic (TNF- $\alpha$ antagonists, tocilizumab, anakinra or rituximab) during follow-up. MDSs/CMML and SIADs had to be diagnosed concomitantly (within 5 years), and cases associated with infectious, treatment-related or neoplastic origin were excluded.

The study was performed in accordance with the ethical standards of the Helsinki Declaration.

\section{Data collection}

We collected data on age, sex, MDSs/CMML features (type, medullar blast number, International Prognostic Scoring System [IPSS] and IPSS-revised [IPSS-R], karyotype, specific treatments), SIAD features and treatments. For each line of SIAD treatment, clinical 
and biological data, steroid amounts and reasons for treatment discontinuation were recorded at the beginning and end of each line of treatment. The different lines of conventional immunosuppressive agents (DMARDs), biologics and specific MDS/CMML treatment (azacytidine) were analysed separately for each patient.

SIAD treatment response was defined as clinical response (complete with disappearance of all symptoms or partial with at least 50\% improvement) and biological response (C-reactive protein level normalization and/or at least 50\% decrease in level). Treatment response was defined at 6 months after treatment initiation or at the time of switch to another drug. Remission was defined as complete clinical and biological response. Steroid dependence was defined as prednisone-equivalent amount $>20 \mathrm{mg} /$ day during at least 2 months. Relapse was defined as active disease after a remission period, which required change of the treatment regimen.

\section{Safety}

All infectious adverse events and infusion-related events were recorded during the follow-up. Severe infection was defined as any infection requiring intravenous antibiotic use or hospitalization or as infection-related death.

\section{Statistical analysis}

Characteristics of subjects are described with medians (interquartile range [IQR]) for quantitative variables and frequency (percentage) for qualitative variables. Mann-Whitney and Fisher exact tests were used to compare quantitative and qualitative variables, respectively. With missing data, data are expressed as percentage taking account of missing data. Overall response, steroid dependence, infections and infusion-related events were compared among treatment regimens by using a Fine and Gray model considering change of treatment as a competing risk (9). Patients with no event were censored at the time of last follow-up. Overall response was compared after adjustment on gender and number of previous treatment lines. Three subjects lacking information on treatment regimens were removed from these analyses. Sequential treatment regimens in the same patient were treated as a time-varying covariate, and a robust variance calculated with a generalized estimating equation approach was computed for regression estimates to account for intra-patient correlations. Cause-specific risk is reported as hazard ratios (HR) and 95\% confidence intervals (CIs). All tests were 2 -sided and $\mathrm{P}<0.05$ was considered statistically significant. Analyses involved use of R 3.3.2. 


\section{RESULTS}

\section{Patient characteristics}

We included 29 patients (median age 67 years [IQR 62-76]; 83\% males). MDSs included refractory anemia with excess blasts 1 (21\%), refractory cytopenia with multilineage dysplasia (38\%), chromosome 5q deletion syndrome (4\%), and CMML (21\%), with median proportion of marrow blasts $2 \%$ (IQR 0-10). The karyotype was normal in 14/24 patients (58\%), with median IPSS 0.5 (0-1.5) and IPSS-R 3 (1-3.3). Overall, 89\%, 14\% and 7\% of patients were at low, intermediate and high risk of MDSs, respectively. Four of 5 patients (80\%) with CMML had CMML-1. MDSs preceded SIADs in 9 patients (32\%), was concomitant in $10(36 \%)$ and occurred after SIADs in the remainder. The median time between MDSs and SIADs diagnosis was 0 months (IQR -60-43).

The associated SIADs were relapsing polychondritis in 9 patients (31\%); arthritis (undifferentiated and rheumatoid arthritis in 3 patients [10\%] each and rhizomelic polyarthritis in one patient); Behcet's disease, cryoglobulinemic vasculitis, giant cell arteritis, and Sweet's syndrome in 2 patients (7\%) each; unclassified vasculitis in 4 patients (14\%) and unclassified systemic disease in 1 patient (3\%). Seven patients showed several SIADs, mainly relapsing polychondritis with Sweet syndrome in 3 patients and unclassified vasculitis in 1 patient.

Steroids alone were used as first-line treatment for 22 patients: $17(77 \%)$ showed overall partial or complete SIAD response. Median C-reactive protein level was significantly decreased after steroids use, from $90 \mathrm{mg} / \mathrm{l}$ (IQR 48-117) $\mathrm{mg} / \mathrm{l}$ at baseline to 15 (4-85) mg/l at the end of treatment $(p=0.02)$. Median prednisone dose significantly decreased from treatment initiation to the end of steroids use alone (60 [IQR 40-60] to $28 \mathrm{mg} /$ day [20-40]; $\mathrm{p}=0.008)$. Second-line treatments were used for steroids dependence in 18 patients $(62 \%)$, inefficacy in $3(10 \%)$, and adverse events and relapse in $3(10 \%)$.

\section{SIAD biologics therapies}

Among 29 patients, 53 lines of biologic therapies were used during follow-up, after a median of 2 (IQR 0-5) lines of DMARDs (methotrexate, $\mathrm{n}=7$; cyclophosphamide, $\mathrm{n}=4$; mycophenolate mofetil, $\mathrm{n}=5$; cyclosporine, $\mathrm{n}=5$; azathioprine, $\mathrm{n}=5$ ). Biologics were prescribed for $89 \%$ of patients because of insufficient control or intolerance to DMARDs and steroids $(\mathrm{n}=26)$ and for $11 \%(\mathrm{n}=3)$ as first-line treatment (Figure 1). The median number of biologic lines was 1 (IQR 1-2), and more than 2 lines were used for 5 patients (18\%). Biologics were TNF- $\alpha$ antagonists for 15 patients (infliximab, $n=11$; etanercept, $n=3$; adalimumab, $\mathrm{n}=1)$, anakinra $(\mathrm{n}=16)$, rituximab $(\mathrm{n}=12)$ and tocilizumab $(\mathrm{n}=10)$ (Figure 1). 
Median biologic treatment duration was 4 months (IQR 2-8). Infliximab was used at a median dose of $5 \mathrm{mg} / \mathrm{kg}$ at weeks 0, 2, 6 and every 6 weeks (IQR 4-8); etanercept at $25 \mathrm{mg}$ twice a week; adalimumab at $40 \mathrm{mg}$ every 2 weeks; tocilizumab at $8 \mathrm{mg} / \mathrm{kg}$ monthly and rituximab at $1 \mathrm{~g}$ twice for $11 / 12$ patients (92\%). Biologics were associated with steroids in 50 patients $(94 \%)$ and other immunomodulatory drugs in 10 (methotrexate, $n=6$; ciclosporine and hydroxychloroquine, $\mathrm{n}=2$ each).

At the initiation of biologic therapies ( $n=53$ lines of biologics), the main SIAD symptoms were non-infectious fever $(n=25 / 53,47 \%)$, arthralgia with arthritis $(n=17 / 53$, $32 \%)$, peripheral neuropathy $(n=5 / 53,9 \%)$ and skin involvement $(n=16 / 53,30 \%)$, with median C-reactive protein level $57 \mathrm{mg} / \mathrm{l}$ (IQR 21-89).

Analyzable data for $7 / 43(16 \%)$ and 13/43 (30\%) patients showed overall response (i.e., complete or partial response, respectively) to 53 lines of biologics. At the end of biologic treatments, $42 / 43$ patients $(98 \%)$ were still under steroids with a median dose of 20 mg/day (IQR 10-30).

During the follow-up, at least one switch was needed for 13/15 patients under TNF- $\alpha$ antagonists (Figure 1A), 13/16 patients under anakinra (Figure 1B), 8/12 patients with rituximab (Figure 1C) and 9/10 patients under tocilizumab (90\%)(Figure 1D).

Considering the efficacy by type of SIADs, biologic therapies allowed for complete or partial improvement of inflammatory arthritis with 9/14 lines of treatment: TNF- $\alpha$ antagonists for $4 / 6$ cases, rituximab for $2 / 2$, anakinra for $1 / 3$ and tocilizumab in $2 / 3$. For patients with vasculitis, complete or partial improvement was noted with 7/19 lines of treatment: 3/7 with rituximab, 2/5 with anakinra, 0/2 with TNF- $\alpha$ antagonists and 2/5 with tocilizumab. Relapsing polychondritis had poor response to biologics, and only $3 / 20$ cases presented an overall response with rituximab, anakinra and infliximab (1 case each).

\section{Comparison of the efficacy of biologics and DMARDs}

DMARDs were used for $14 / 29$ patients before biologic therapies (methotrexate, $n=7$; cyclophosphamide, $n=4$; mycophenolate mofetil, $n=5$; cyclosporine, $n=5$; azathioprine, $n=5$ ). Overall 26 lines of DMARDs were used with a median of DMARD lines before biologics of 1 (IQR 0-1), and 5 patients received 3 or more DMARDs before biologics. The median dose of steroids at the beginning of biologic therapies was 25 (20-35) versus $25 \mathrm{mg} /$ day (16-35) at DMARD initiation ( $\mathrm{p}=0.4$ ), with median C-reactive protein level 31 (13-78) vs 53 mg/l (39120) for DMARDs $(\mathrm{p}=0.03)$. For analyzable lines, a complete and partial response to DMARDs versus biologics was noted for $1 / 21$ (5\%) and 7/21 (33\%) versus 7/43 (16\%) and $13 / 43(30 \%)$, respectively $(\mathrm{p}=0.4)$. 


\section{Efficacy of different biologics and azacytidine}

Overall response (i.e., complete and partial response) occurred for $31 \%$ of patients with TNF$\alpha$ antagonists, 25\% anakinra, 33\% tocilizumab and 58\% rituximab (Table 1, Figure 2). On comparing response rates to that with steroids (considered as reference), clinical remission was lower with DMARDs, TNF- $\alpha$ antagonists and anakinra (HR: 0.18 [95\% CI 0.03-0.95], 0.17 [0.05-0.60] and 0.26 [0.07-0.93], $\mathrm{p}<0.05$, respectively) but did not differ for rituximab and azacytidine (HR: 0.49 [0.15 1.60] and 0.40 [0.09-1.80], p>0.05) (Figure 2). Steroid dependence rate in comparison to anakinra was greater with TNF- $\alpha$ antagonists (HR: 13.89 [1.46-132.3], $\mathrm{p}<0.03$ ), DMARDs (HR: 19.99 [1.82-219.6], $\mathrm{p}<0.04)$ and rituximab (HR: 11.92 [1.17-121.1], p <0.04) (Figure 3). Ten patients received azacytidine for underlying MDSs and/or steroid-dependent or refractory SIADs after a median of 4 lines (IQR 3-6) of SIAD treatments. Half of the patients showed hematological complete response, and 5/7 evaluable patients (68\%) showed SIAD overall response (i.e., partial and complete). Steroid doses and C-reactive protein level decreased with azacytidine, from $25 \mathrm{mg} /$ day and $44 \mathrm{mg} / \mathrm{l}$ at baseline to $20 \mathrm{mg} /$ day and $3 \mathrm{mg} / \mathrm{l}$, respectively (Table $\mathbf{1}$ ).

\section{Safety}

During a median follow-up of 36.5 months (IQR 16-70), 41 adverse effects were noted. In total, 18/29 patients (a total of 30 infections) showed severe infections. Infections were bacterial: lung $(n=12)$, urinary tract $(n=4)$; undetermined bacteriemia $(n=2)$, skin $(n=1)$ and other sites; viral B19 reactivation $(n=2)$ and fungal infection $(n=2)$. Infections occurred under steroids treatment alone with 5 lines of treatment (20\%), DMARDs in $15 \%$ of patients $(n=5)$, biologics (all included) in 29\% and azacytidine in 60\% $(n=6)$ (Table 1). Infection rates did not differ with biologics, DMARDs and azacytidine versus steroids alone (HR: 0.76 [95\% CI: $0.14-4.2], p=0.76 ; 0.18$ [0.01-2.86], $\mathrm{p}=0.22$ and 0.87 [0.1-7.69], $\mathrm{p}=0.9$; respectively) (Figure 4).

Injection-related reactions occurred in $21 \%$ of patients $(n=11$ lines of treatment) and led to treatment discontinuation in 8 (15\%). Injection-related reactions occurred with anakinra $(n=5)$, tocilizumab $(n=4)$, adalimumab $(n=1)$ and infliximab $(n=1)$. Biologics were discontinued because of injection reaction related to anakinra $(n=4)$, tocilizumab $(n=2)$ and infliximab $(n=1)$. Injection-related reaction rates versus anakinra were significantly lower with DMARDs (HR: 0.33 [95\% CI 0.12-0.92], p=0.033) but not tocilizumab and TNF- $\alpha$ antagonists (0.49 [0.05-4.98], $\mathrm{p}=0.55$ and 0.39 [0.05-3.03], $\mathrm{p}=0.37$ ) (Figure 5). Ten patients (34\%) died at a median time since MDS diagnosis of 21 months (IQR 3-123), mainly from 
infection in $91 \%$ and acute leukemia in the remainder. The IPSS and IPSS-R, steroids doses at the last visit, and number of immunosuppressive lines did not differ among patients who did and did not die, and under azacytidine, 2 died as compared with 8 who were alive at the last visit.

\section{Discussion}

We report the difficulty in controlling SIAD-related MDSs, here showing a median of 4 lines (IQR 3-5) of treatment required, despite a 77\% overall initial response to steroids alone. In contrast to SIADs without underlying MDSs/CMML, except for rituximab, biologic therapies had poor efficacy, with only $44 \%$ complete and partial response. Rituximab seemed more efficient, with an overall $58 \%$ response, mainly in vasculitis. The rate of adverse effects was particularly high (62\% of infections and $21 \%$ of injection-related reactions) in the context of underlying MDSs and induced immunosuppression, which led to frequent discontinuation.

Treatment of SIAD-related MDS is challenging, with usually a high steroiddependence rate and risk of infections favored by cytopenia associated with MDS (10-14). Although usually steroids achieve good response, the steroid-sparing strategy and the response rates of various immunosuppressive drugs are poorly reported (10-14). Several previous studies showed insufficient response to TNF- $\alpha$ antagonists for MDSs alone but relatively acceptable safety profile $(4,15)$. Some case reports showed controversial data about MDS-related SIAD remission with biologics, such as a case of vasculitis associated with arthralgia that responded to TNF- $\alpha$ inhibitors (5-7)(10). Even though we reported on various SIADs, the biologics efficacy seems to be much lower in MDS-related disorders than non MDS-related SIADs (16). Intravenous immunoglobulins are widely used in the setting of various immune disorders, in particular as salvage therapy in immune thrombocytopenia, inflammatory myositis or adult Still's disease (17). The risk of infectious complication could be another reason to use intravenous immunoglobulins in this subset of patients, even only few case reports reported its use in the dysimmune features associated with myelodysplastic syndromes (18).

In our study, the response varied by type of biologics, with low efficacy for TNF- $\alpha$ inhibitors, tocilizumab and interleukin-1 inhibitors. Rituximab allowed for an overall relatively good response, but the response seemed to vary by type of manifestations. With predominantly articular manifestations, TNF- $\alpha$ inhibitors can be efficient, whereas in systemic vasculitis, rituximab should be chosen. Interestingly, steroid-sparing rates, an important goal in the MDS context, significantly decreased only with rituximab and azacytidine. Azacytidine showed an overall response of $67 \%$ for SIADs with MDSs, which 
could argue for a pathophysiological link between these 2 diseases. Although azacytidine was used after several lines of treatment, it allowed for steroid sparing, as we previously reported, with the known risk of infection (8).

Safety is important to consider because of the increase in infectious events in MDSs and the use of immunosuppressive agents. Sullivan et al. described an infectious risk of about $15 \%$ during the first year after the MDS diagnosis, which seems to be similar with the different biologics treatments in our study (19). In light of the injection-related events, a high rate of reaction was noted with all biologics except rituximab, requiring treatment discontinuation in $29 \%$.

Our study has several limitations. The retrospective design of this case series, the low number of patients receiving treatment with each drug and the analysis of treatment lines should limit definitive conclusions, even if these analyses were adjusted on number of treatment lines. The selection bias is implicated because we selected patients who needed biologic therapies, and thus patients with favorable outcomes with steroids alone or steroidsparing drugs were not included. Similarly, the efficacy of DMARDs could be underestimated because all patients needed biologics, even if steroid dependence was the main reason for the drug switch. The use of various biologics was left to the physician's discretion and could be heterogeneous in the absence of clinical guidelines, and the biological response by using C-reactive protein level could be biased for tocilizumab.

\section{Conclusion}

Biologics may not be the most appropriate treatment for MDS-related SIADs and do not reduce the dose of corticosteroids and risk of infection. The favorable response of these associated manifestations to MDS treatment with azacytidine encourages earlier treatment, before a long duration of treatment with corticosteroids, immunosuppressants or biologics and independent of the type of MDS. Prospective randomized studies are required to confirm these conclusions and an open-labelled study is ongoing in France. 
Figure 1. Flow-charts of patient treatments by biologic-targeted drug treatments.

Figure 2. Hazards ratios of treatment response in comparison to steroids for biologic-targeted treatments, disease-modifying anti-rheumatic drugs (DMARDs) and azacitidine.

Figure 3. Steroid-dependence rates with various biologic-targeted treatments, DMARDs and azacitidine.

Figure 4. Infections with various biologic-targeted treatments, DMARDs and azacitidine.

Figure 5. Injection-related events with various biologic-targeted treatments and DMARDs. 
Table 1. Overall response to and safety of all lines of treatment ( $n=114$ lines) for systemic inflammatory and autoimmune diseases (SIADs).

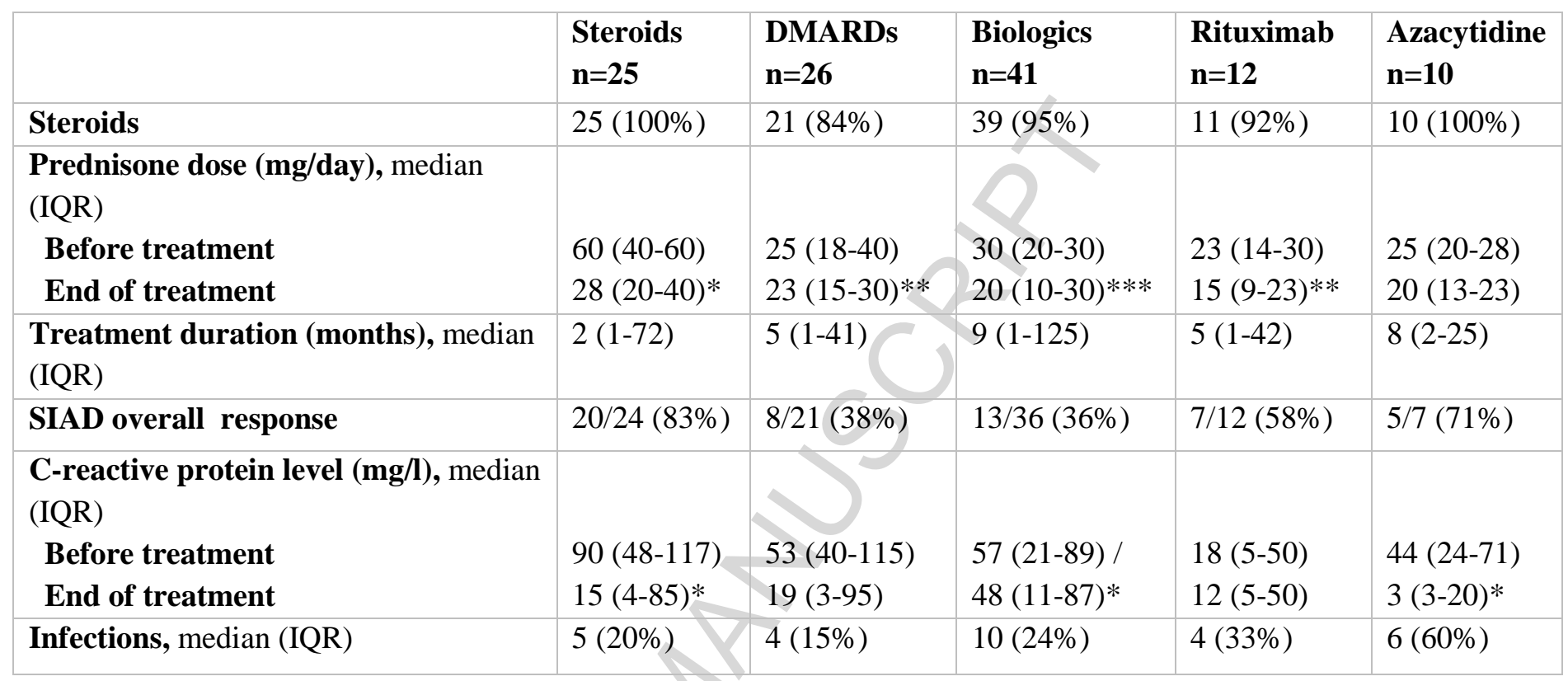

Data are $\mathrm{n}(\%)$ unless indicated. $* \mathrm{p}<0.05$ before vs end of treatment

$* * \mathrm{p}=0.07$ before vs end of treatment $* * * \mathrm{p}=0.09$ before vs end of treatment 


\section{References}

1. Mekinian A, Grignano E, Braun T, Decaux O, Liozon E, CostedoatChalumeau N, et al. Systemic inflammatory and autoimmune manifestations associated with myelodysplastic syndromes and chronic myelomonocytic leukaemia: a French multicentre retrospective study. Rheumatology (Oxford). 2015.

2. Mekinian A, Braun T, Decaux O, Falgarone G, Toussirot E, Raffray L, et al. Inflammatory arthritis in patients with myelodysplastic syndromes: a multicenter retrospective study and literature review of 68 cases. Medicine (Baltimore).93(1):1-10.

3. Baron F, Suciu S, Amadori S, Muus P, Zwierzina H, Denzlinger C, et al. Value of infliximab (Remicade(R)) in patients with low-risk myelodysplastic syndrome: final results of a randomized phase II trial (EORTC trial 06023) of the EORTC Leukemia Group. Haematologica. 2012;97(4):529-33.

4. Stasi R, Amadori S, Newland AC, Provan D. Infliximab chimeric antitumor necrosis factor-a monoclonal antibody as potential treatment for myelodysplastic syndromes. Leuk Lymphoma. 2005;46(4):509-16.

5. Kimura S, Kuroda J, Akaogi T, Hayashi H, Kobayashi Y, Kondo M. Trisomy 8 involved in myelodysplastic syndromes as a risk factor for intestinal ulcers and thrombosis--Behcet's syndrome. Leuk Lymphoma. 2001;42(1-2):115-21.

6. Pipitone N, Masini L, Salvarani C. A case of arthritis and vasculitis associated with the refractory anemia with excess of blasts syndrome resistant to glucocorticoid treatment that responded favorably to TNF-alpha blockade. Clinical and experimental rheumatology. 2006;24(2 Suppl 41):S31-4.

7. Toyonaga T, Nakase H, Matsuura M, Minami N, Yamada S, Honzawa Y, et al. Refractoriness of intestinal Behcet's disease with myelodysplastic syndrome involving trisomy 8 to medical therapies - our case experience and review of the literature. Digestion. 2013;88(4):217-21.

8. Fraison JB, Mekinian A, Grignano E, Kahn JE, Arlet JB, Decaux O, et al. Efficacy of Azacitidine in autoimmune and inflammatory disorders associated with myelodysplastic syndromes and chronic myelomonocytic leukemia. Leukemia research. 2016;43:13-7.

9. Fine JP GR. A proportional hazards model for the subdistribution of a competing risk. . J Am Stat Assoc. 1999;94(496-509.).

10. Al Ustwani O, Ford LA, Sait SJ, Block AM, Barcos M, Vigil CE, et al. Myelodysplastic syndromes and autoimmune diseases--case series and review of literature. Leukemia research.37(8):894-9.

11. Al Ustwani O, Francis J, Wallace PK, Ambrus J, Jr., Wetzler M. Treating myelodysplastic syndrome improves an accompanying autoimmune disease along with a reduction in regulatory T-cells. Leukemia research.35(5):e35-6.

12. de Hollanda A, Beucher A, Henrion D, Ghali A, Lavigne C, Levesque H, et al. Systemic and immune manifestations in myelodysplasia: a multicenter retrospective study. Arthritis Care Res (Hoboken).63(8):1188-94.

13. Enright H, Jacob HS, Vercellotti G, Howe R, Belzer M, Miller W. Paraneoplastic autoimmune phenomena in patients with myelodysplastic syndromes: response to immunosuppressive therapy. $\mathrm{Br} \mathrm{J}$ Haematol. 1995;91(2):403-8.

14. Enright $\mathrm{H}$, Miller W. Autoimmune phenomena in patients with myelodysplastic syndromes. Leuk Lymphoma. 1997;24(5-6):483-9. 
15. Deeg HJ, Gotlib J, Beckham C, Dugan K, Holmberg L, Schubert M, et al. Soluble TNF receptor fusion protein (etanercept) for the treatment of myelodysplastic syndrome: a pilot study. Leukemia. 2002;16(2):162-4.

16. Pazzola G, Muratore F, Pipitone N, Salvarani C. Biologics in vasculitides: Where do we stand, where do we go from now? Presse Med. 2015;44(6 Pt 2):e231-9.

17. Sanges S, Riviere S, Mekinian A, Martin T, Le Quellec A, Chatelus E, et al. Intravenous immunoglobulins in systemic sclerosis: Data from a French nationwide cohort of 46 patients and review of the literature. Autoimmun Rev. 2017;16(4):377-84.

18. Komrokji RS, Kulasekararaj A, Al Ali NH, Kordasti S, Bart-Smith E, Craig $\mathrm{BM}$, et al. Autoimmune diseases and myelodysplastic syndromes. American journal of hematology. 2016;91(5):E280-3.

19. Sullivan LR, Sekeres MA, Shrestha NK, Maciejewski JP, Tiu RV, Butler R, et al. Epidemiology and risk factors for infections in myelodysplastic syndromes. Transplant infectious disease : an official journal of the Transplantation Society. 2013;15(6):652-7. 


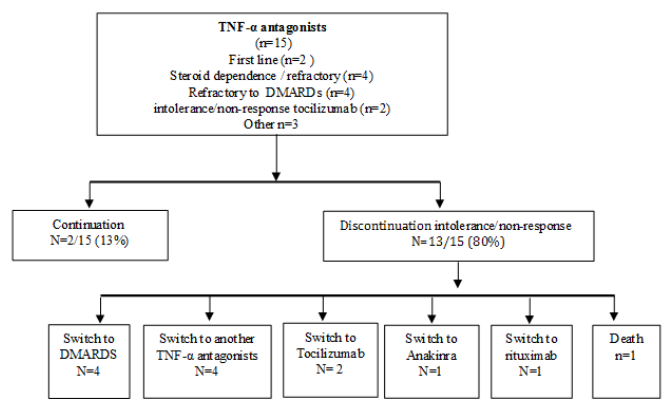

Figure 1A 


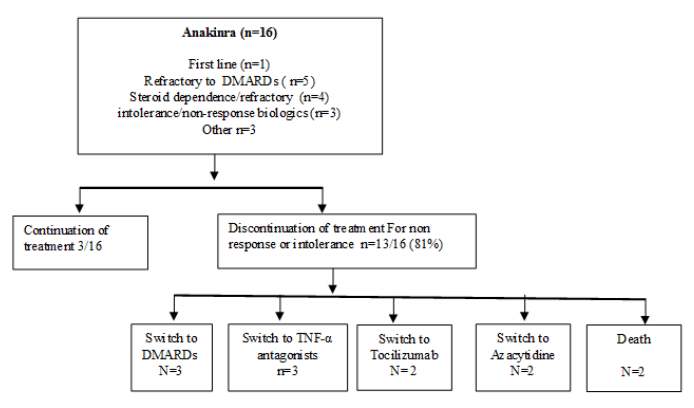

Figure 1B 


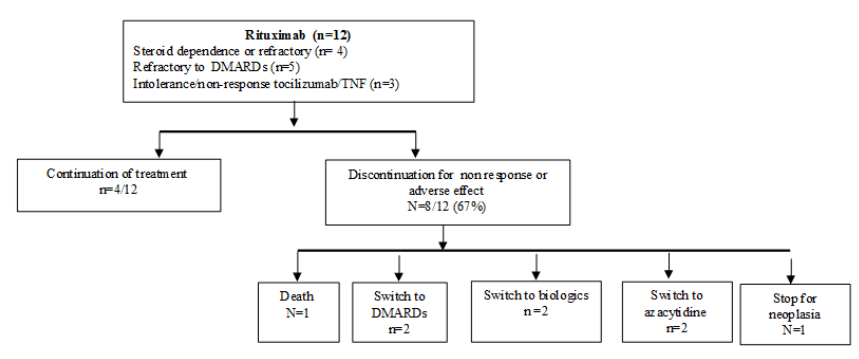

Figure 1C 


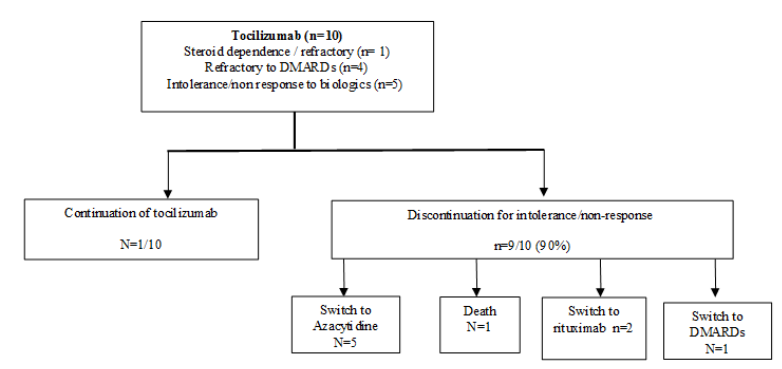

1D

Figure 1D 


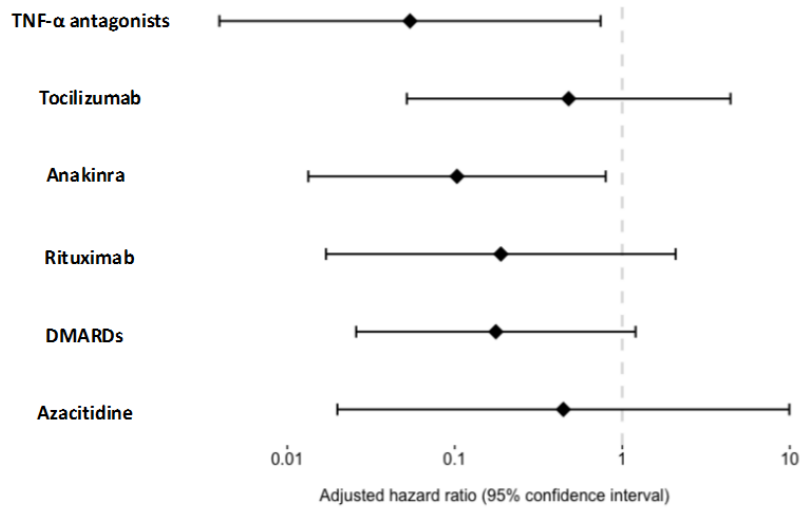

Figure 2 


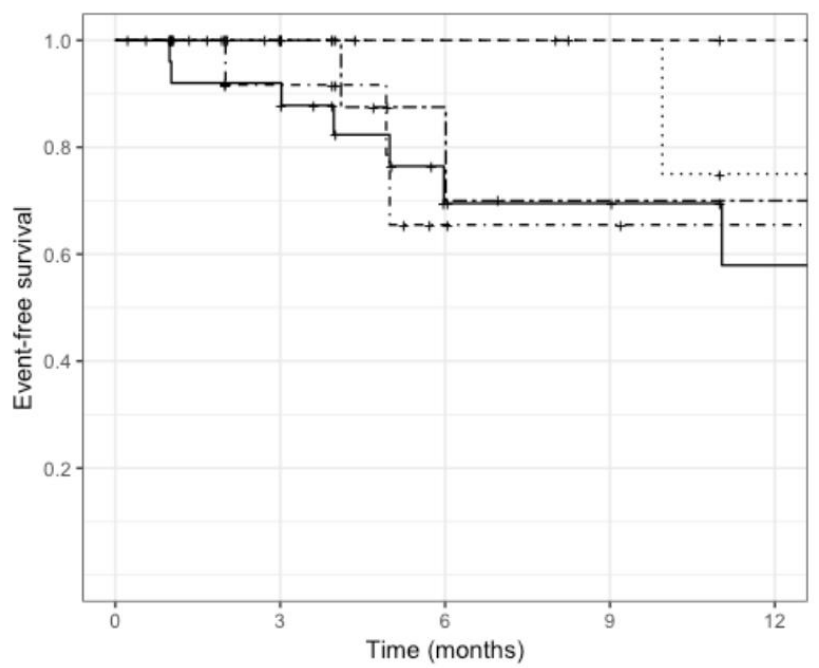

Treatment

- DMARDs

- - Anakinra

.-. Anti-TNF $\alpha$

--. Rituximab

.... Azacitidine

Figure 3 

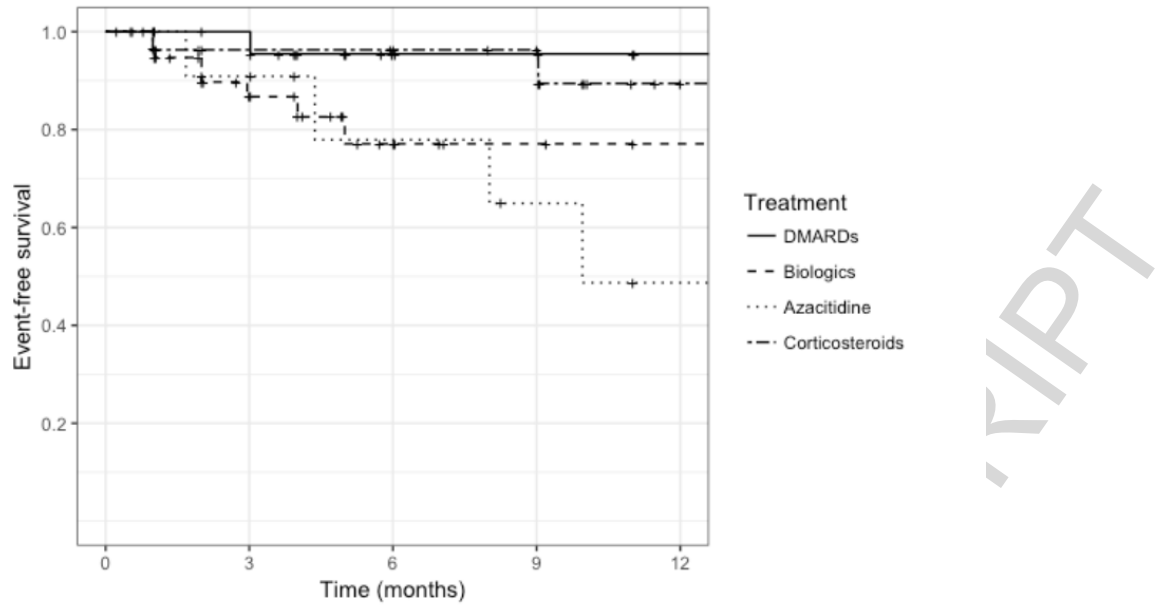

Figure 4 


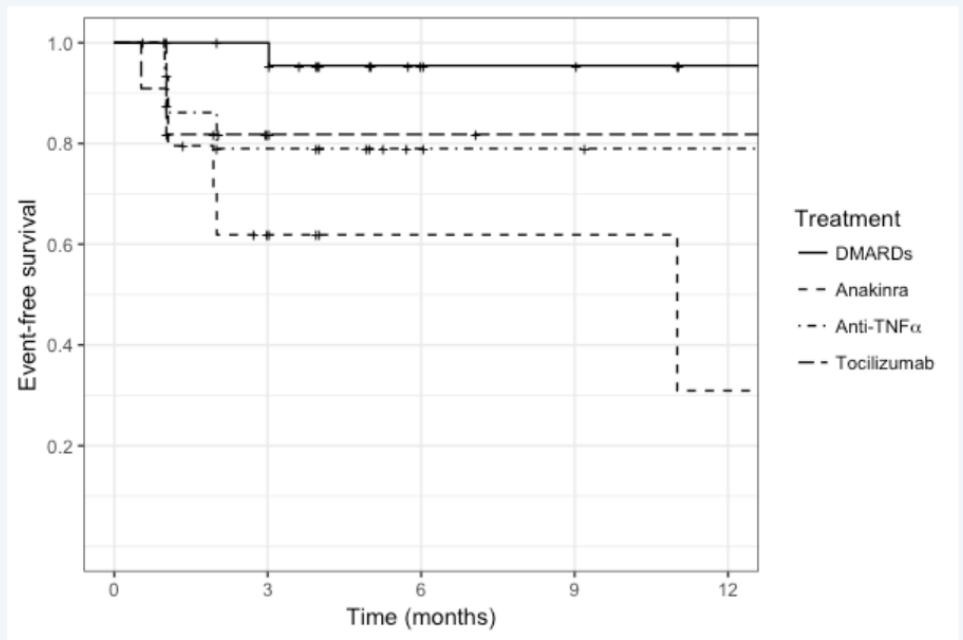

Figure 5 